\title{
Is health needs of chronic disease patients addressed during COVID-19 lockdown in India? A cross-sectional survey
}

\author{
Aby Paul ( $\sim$ 26abypaul@gmail.com ) \\ Nirmala college of Pharmacy \\ Joel Joby \\ Nirmala College of Pharmacy \\ Sanjo Saijan \\ Nirmala College of Pharmacy \\ Jude James \\ Nirmala College of Pharmacy \\ Stelvin Sebastian \\ Nirmala College of Pharmacy \\ Basil John \\ Nirmala College of Pharmacy \\ Edwin Antony \\ Nirmala College of Pharmacy \\ Jobin Kunjumon \\ Nirmala College of Pharmacy
}

\section{Research}

Keywords: Covid-19, lockdown, chronic illness, cardiovascular metabolic co-morbidities, autoimmune rheumatic diseases

Posted Date: June 22nd, 2020

DOl: https://doi.org/10.21203/rs.3.rs-36957/v1

License: (c) (i) This work is licensed under a Creative Commons Attribution 4.0 International License. Read Full License 


\section{Abstract}

\section{Background}

The novel corona virus disease (COVID-19) was declared as pandemic by World health organisation (WHO) on the $11^{\text {th }}$ of March 2020. India was one among the countries in the world to declare the longest lock down across the nation in order to resist the spread of COVID-19. It was a challenge to assess the medical care of chronic disease patients during these lock down days.

\section{Methodology}

We adopted a cross sectional survey design to assess the health conditions and perceptions of patients with cardiovascular metabolic co-morbidities and those with autoimmune rheumatic diseases during the COVID-19 lock down days

\section{Results and Discussion}

A total of 310 patients completed the survey during this time period. Among these 310 responders, 299 completed the survey. We had $157(52.50 \%)$ patients with cardiovascular metabolic co-morbidities and $142(47.49 \%)$ with autoimmune rheumatic diseases. The mean age of patients in cardiovascular metabolic co-morbidities group was found to be $59.19 \pm 16.34$ and those in autoimmune rheumatic diseases was $47.05 \pm 13.30$. The predominant distribution of female gender for cardiovascular metabolic co-morbidities (57.32\%) group and autoimmune rheumatic diseases (72.53\%) is in accordance all the previous studies in this field.. The women are found to react more negatively in terms of to the same traumatic stress when compared with men

\section{Conclusion}

In conclusion there is strong need for health policy reformations in the field of the chronic diseases health care management to equip the preparedness in order respond adequately to such medical emergencies including natural disaster

\section{Background}

The novel corona virus disease (COVID-19) was declared as pandemic by World health organisation (WHO) on the $11^{\text {th }}$ of March 2020 [1]. The recently struck pandemic of COVID-19 had created a great concern among chronic disease patients about their disease status and continuation of their treatment. Many studies have proved that the cardiovascular metabolic co-morbidities were associated with greater risk and complications of COVID-19. A meta-analysis from China stated that the most prevalent cardiovascular metabolic co-morbidities that complicated the treatment of COVID-19 patients were hypertension (17.1\%, 95\% Cl 9.9 - 24.4\%), cardio-cerebrovascular disease $(16.4 \%, 95 \% \mathrm{Cl} 6.6-26.1 \%)$ and diabetes $(9.7 \%, 95 \% \mathrm{Cl} 6.9-12.5 \%)$. Patients with diabetes or hypertension had a 2 -fold increase in the risk of severe disease or required intensive care unit (ICU) admission, while those with cardio- 
cerebrovascular disease exhibited a 3-fold increase [3]. Patients with autoimmune rheumatic diseases were also left with great uncertainty during this COVID-19 period. Some of the reasons that were proposed for this uncertainty included the anxiety of acquiring COVID-19 in immune suppressed patients, as majority of the rheumatic patients will be in an immunocompromised state either due to disease or treatment. The scare availability of immune-modulators like hydroxychloroquine (HCQs) was also a factor of concern since a worldwide press coverage was already out suggesting that HCQs was efficient in treating COVID-19. [4]

India was one among the countries in the world to declare the longest lock down across the nation in order to resist the spread of COVID-19. Till date India competed 4 phases of nationwide lockdown of which phase 1 being initiated on March $25^{\text {th }}, 2020$ [5]. It was a challenge to assess the medical care of chronic disease patients during these lock down days. None of the studies from India have assessed the health conditions of chronic disease patients and their assess ability to medical care during the hard days of lock down. Therefore we conducted a cross sectional study which emphasized on the health conditions and perceptions of patients with cardiovascular metabolic co-morbidities and those with autoimmune rheumatic diseases during the COVID 19 induced lock down days.

\section{Methodology}

Settings and participants

We adopted a cross sectional survey design to assess the health conditions and perceptions of patients with cardiovascular metabolic co-morbidities and those with autoimmune rheumatic diseases during the COVID-19 lock down days. We used an anonymous online questionnaire to obtain the responses. A snowball sampling strategy was adopted to recruit patients into the study. The target population were the chronic disease patients living in the state of Kerala. The online survey was first disseminated among the students of Nirmala college of Pharmacy, Muvattupuzha and to the patients of a rheumatology center in the area via social Medias.

\section{Procedure}

As the Indian Government strictly wanted their citizens to minimize the social contact and to remain in their homes, potential respondents were electronically invited to take up the survey. The questionnaire was prepared in English using Google forms. Language assistance and queries of the participants were attended and clarified on phone via the telephone number provided along with the request message attached with the Google form link circulated in different social Medias. All respondents attended the electronic informed consent which contained clear information that only patients who had cardiovascular metabolic co-morbidities (Coronary artery disease, Myocardial infraction, Diabetes, Hypertension , Dyslipedemia , Stroke etc) and patients with autoimmune rheumatic diseases (Rheumatoid arthritis , Anklosing spondylyties , Psoriatic arthritis , Lupus , Scleroderma , Bechets etc ) are eligible to take up the survey. Responses were accepted for a period of 10 days extending from 27 April 2020 - May 12, 2020. 
Study Development

The survey questionnaire consisted of 19 questions covering the socio-demographics, health service utilisation, health conditions, and health concerns along with a numerical rating scale to assess the personal perceptions of the participant about their health status.

Socio-demographic obtained included age(1), gender(2), educational background(3), their chronic disease(4), the time period since they are diagnosed with the chronic condition (5), The sector of hospital (Government/Private) and the type of Physician (General/Specialist) from where the patients take their treatment is also asked.(6,7) The respondents were asked for their details on the health services utilization (mainly dichotomous questions) provided to them during these lockdown days. The questions included whether they could assess their regular physician visits(8), accessibility to telemedicine(9), laboratory checkups(10), the availability of medications at their local pharmacy(11), strategies they adopted to procure their medications(12) and the immediate health care provider whom they were able to assess during this lock down period. (13) The health conditions and health concerns were evaluated with a set of dichotomous questions and numerical rating scales (NRS). The numerical rating scales ranged from 0 to 10. In this 0 was rated as not worried or satisfactory and 10 as worried or not satisfactory. The dichotomous questions included were whether they had any flare of symptoms during this lock down (14), and if they were worried about acquiring COVID-19 infection while visiting the hospital (15). NRS questions were evaluated to rate their concerns on reduced access to health care during the lock down days(16), concerns regarding the safety of medicines they were consuming during the lock down period (17) and their concerns about acquiring COVID-19 infections because of their chronic disease state(18) and their overall wellbeing during this lockdown. (19)

Statistical Analysis

Descriptive statistics were calculated for age and NRS questions. Patients were classified into 2 disctinct disease categories; patients who have cardiovascular metabolic co-morbidities (Coronary artery disease , Myocardial infarction, Diabetes, Hypertension , Dyslipedemia , Stroke etc ) and patients with autoimmune rheumatic diseases ( Rheumatoid arthritis, Anklosing spondylyties, Psoriatic arthritis , Lupus, Scleroderma , Bechets etc ).Patients having autoimmune rheumatic disease along with cardiovascular metabolic co-morbidities were considered in autoimmune rheumatic disease group for statistical analysis. Percentage of response was calculated according to the number of respondents per response with respect to the number of total response of a question in each group. We used Chi-square test to analyse the association between the categorical variables in both disease groups. T-test was used to analyse the age and for NRS questions in both disease groups. We assessed the independent factors associated with using bi-variate logistic regression analysis All test were two- tailed, with significance level of $p<0.05$. Statistical analysis was performed using SPSS statistics 21.0 (IBM SPSS Statistics, New York, United States).

\section{Results}


Survey responses were accepted from 27 April 2020 to 10 May 2020. The survey was conducted nearly one month since the nationwide lock down in India was declared [5].

A total of 310 patients completed the survey during this time period. Among these 310 responders, 299 completed the survey. They were then classified as patients with cardiovascular metabolic co-morbidities (Coronary artery disease, Myocardial infarction, Diabetes, Hypertension, Dyslipedemia , Stroke etc) and patients with autoimmune rheumatic diseases (Rheumatoid arthritis, Anklosing spondylyties, Psoriatic arthritis , Lupus , Scleroderma , Bechets etc ). We had 157(52.50\%) patients with cardiovascular metabolic co-morbidities and 142(47.49\%) with autoimmune rheumatic diseases.

Socio-demographic characteristics

The socio-demographic factors being analysed included age, gender, and educational background. The disease demographics of the patient were also assessed. These characteristics included disease activity and the time period since they are diagnosed with the disease. These socio-demographic characteristics are presented in Table 1.

Table 1: Comparison of socio-demographic characteristics among patient groups. 


\begin{tabular}{|c|c|c|c|c|}
\hline $\begin{array}{l}\text { Socio- } \\
\text { demographic } \\
\text { characteristics }\end{array}$ & $\begin{array}{l}\text { Options for } \\
\text { respondents }\end{array}$ & $\begin{array}{l}\text { cardiovascular } \\
\text { metabolic co- } \\
\text { morbidities }(n=157)\end{array}$ & $\begin{array}{l}\text { Autoimmune } \\
\text { rheumatic } \\
\text { diseases }(n=142)\end{array}$ & $\begin{array}{l}\text { P value } \\
\text { (2-tailed } \\
\text { test) }\end{array}$ \\
\hline Age(Mean \pm Std.Dev) & & $59.197 \pm 16.34$ & $47.05 \pm 13.30$ & 0.000 \\
\hline \multirow[t]{2}{*}{ Gender } & Male(n=106) & $67(42.67 \%)$ & $39(27.46 \%)$ & \multirow[t]{2}{*}{0.008} \\
\hline & Female(n=193) & $90(57.32 \%)$ & $103(72.53 \%)$ & \\
\hline \multirow{4}{*}{$\begin{array}{l}\text { Educational } \\
\text { Background }\end{array}$} & High School $(n=116)$ & $94(59.87 \%)$ & $22(15.49 \%)$ & \multirow{4}{*}{0.000} \\
\hline & Undergraduate $(n=111)$ & $47(29.93 \%)$ & $64(45.07 \%)$ & \\
\hline & Post graduate $(n=64)$ & $11(7.00 \%)$ & $53(37.32 \%)$ & \\
\hline & $\begin{array}{l}\text { Doctor of } \\
\text { Philosophy }(n=8)\end{array}$ & $5(3.18 \%)$ & $3(2.11 \%)$ & \\
\hline \multirow{3}{*}{$\begin{array}{l}\text { Disease activity } \\
\text { period }\end{array}$} & $<2$ years $(n=135)$ & $72(45.85 \%)$ & $63(44.36 \%)$ & \multirow{3}{*}{0.006} \\
\hline & $2-5$ years $(n=89)$ & $36(22.92 \%)$ & $53(37.32 \%)$ & \\
\hline & $>5$ years $(n=75)$ & $49(31.21 \%)$ & $26(18.30 \%)$ & \\
\hline \multirow[t]{2}{*}{ Type of hospital } & $\begin{array}{l}\text { Government } \\
\text { Sector }(n=69)\end{array}$ & $62(39.49 \%)$ & $7(4.92 \%)$ & \multirow[t]{2}{*}{0.000} \\
\hline & Private Sector $(n=230)$ & $95(60.50 \%)$ & $135(95.07 \%)$ & \\
\hline \multirow[t]{2}{*}{$\begin{array}{l}\text { Type of } \\
\text { Physician }\end{array}$} & $\begin{array}{l}\text { General } \\
\text { Physician }(n=89)\end{array}$ & $75(47.77 \%)$ & $14(9.85 \%)$ & \multirow[t]{2}{*}{0.000} \\
\hline & Specialist $(\mathrm{n}=210)$ & $82(52.22 \%)$ & $128(90.14 \%)$ & \\
\hline
\end{tabular}

Comparison of socio-demographic characteristics among patient groups: We compared the continuous variables using T-test and categorical variables using Chi-square test. All test were two- tailed, with significance level of $p<0.05$.

The mean age in years of patients in cardiovascular metabolic co-morbidities group was found to be $59.19 \pm 16.34$ and those in second group was $47.05 \pm 13.30$. Patients with autoimmune rheumatic diseases were comparatively younger than those with cardiovascular metabolic co-morbidities $(p<0.05)$. Majority of respondents were females (64.54\%). Females constituted,(72.53\%) of all patients in the autoimmune rheumatic diseases. The gender distributions in the both disease had statistically significant difference $(p<0.05)$. The educational background of the patients were reported to have statistically significant difference among both the study groups $(\mathrm{p}<0.05)$. Our survey participants comprised of those who studied up to high school (38.79\%), Undergraduate (37.12\%), Post graduate (21.40\%) and doctor of Philosophy holders (2.67\%) respectively. Among the patients with cardiovascular metabolic comorbidities, majority of the patients had educational qualification of high school level (59.87\%). In 
contrast majority of patients with autoimmune rheumatic diseases had an educational of undergraduate level (45.07\%). The disease activity period were studied and patients with disease activity period greater than 5 years were significantly higher in the cardiovascular metabolic co-morbidities group (31.21\%) when compared with the patients of autoimmune rheumatic diseases group (18.30\%). The Sociodemographic characteristic of disease activity had statistically significant difference among both the disease group $(p<0.05)$. Patients in the cardiovascular metabolic co-morbidities group depended on $39.49 \%$ depended government hospitals in contrary only $4.92 \%$ of patients in the autoimmune rheumatic disease group depended on government treatment $(p<0.05)$. The type of physician that the patients relied for their treatment was also asked. In the disease groups $52.22 \%$ and $90.14 \%$ of patients relied on specialised care in the cardiovascular metabolic co-morbidities group and autoimmune rheumatic diseases group respectively.

Health care service utilisation characteristics

In order to analyse the health care service utilisation of the patients during the lockdown days we used a set of six questions. Among these four were dichotomous questions and the remaining two questions were provided with multiple options. The responses for the same are presented in Table 2

We found that only $52.22 \%$ of patients with cardiovascular metabolic co-morbidities could conduct their regular physician visits, while $71.83 \%$ of patients with autoimmune rheumatic diseases had their regular physician visit. These results were also be supported by the fact that $68.30 \%$ of patients in autoimmune rheumatic diseases had access to telemedicine. Both these health care service utilisation characteristics showed statistically significant difference $(p<0.05)$ between both the study groups. The patient access to their regular laboratories was also assessed. Among 299 patients, $54.51 \%$ patients has access to their regular laboratories of which $52.22 \%$ of patients were from cardiovascular metabolic co-morbidities group compared to $57.74 \%$ of patients from autoimmune rheumatic diseases group $(P>0.05)$. The patients were asked about the availability of their medicines at the local pharmacy. Among the respondents $78.98 \%$ of patients in the cardiovascular metabolic co-morbidities were able to procure their medicines from the local pharmacies whilst only $30.98 \%$ of patients with autoimmune rheumatic diseases did the same $(p<0.05)$. The strategies adopted by the patients to procure their medicines were analysed. Majority of patients with cardiovascular metabolic co-morbidities $41.40 \%$ depended on their relatives to get their medicines whereas only $4.45 \%$ discontinued their regular medicines. Among patients with autoimmune rheumatic diseases majority of the patients $44.36 \%$ bought their medicines on their own and $3.52 \%$ discontinued their medicines $(P>0.05)$. The patients were also enquired about the most assessable healthcare professionals during the COVID-19 lockdown days. Responses from patients with cardiovascular metabolic co-morbidities were doctors (26.75\%), nurses (10.82\%), pharmacist $(10.8 \%)$ followed by other allied health professionals,(51.59\%). The most immediate approachable health care person for those with autoimmune rheumatic disease were doctors $(57.04 \%)$ followed by nurses $(5.63 \%)$, followed by pharmacists $(19.71 \%)$ and other allied health professionals $(17.60 \%)$ respectively. 
We assessed the health conditions and concerns of chronic disease patients during COVID-19 lockdown. We utilised a set of six questions for this and the results are presented in Table 3.

\section{Table 2: Comparison of health care service utilization among the patient groups.}

\begin{tabular}{lllll}
$\begin{array}{l}\text { Health conditions and } \\
\text { concerns }\end{array}$ & $\begin{array}{l}\text { Options for } \\
\text { respondents }\end{array}$ & $\begin{array}{l}\text { cardiovascular } \\
\text { metabolic co- } \\
\text { morbidities(n=157) }\end{array}$ & $\begin{array}{l}\text { Autoimmune } \\
\text { rheumatic } \\
\text { diseases(n=142) }\end{array}$ & $\begin{array}{l}\text { P value } \\
\text { (2-tailed } \\
\text { test) }\end{array}$ \\
\hline $\begin{array}{l}\text { Flare of symptoms during } \\
\text { lockdown }\end{array}$ & Yes $(n=76)$ & $43(27.38 \%)$ & $33(23.23 \%)$ & 0.428 \\
\cline { 2 - 4 } & No(n=223) & $114(72.61 \%)$ & $109(76.76 \%)$ & \\
\hline $\begin{array}{l}\text { Worried about acquiring } \\
\text { COVID-19, If they visit } \\
\text { hospitals }\end{array}$ & Yes $(n=188)$ & $103(65.60 \%)$ & $85(59.85 \%)$ & \\
\cline { 2 - 4 } & No(n=111) & $54(34.39 \%)$ & $57(40.14 \%)$ & 0.338 \\
\hline
\end{tabular}

Numerical Rating Scale (0-not worried or satisfactory , 10-worried or not satisfactory)

\begin{tabular}{|c|c|c|c|}
\hline $\begin{array}{l}\text { Reduced access to health care services } \\
\text { (Mean } \pm \text { Std.Dev) }\end{array}$ & $4.363 \pm 2.902$ & $4.620 \pm 3.430$ & 0.484 \\
\hline $\begin{array}{l}\text { Concerns regarding the medicines they use } \\
\text { in COVID-19 season (Mean } \pm \text { Std.Dev) }\end{array}$ & $4.344 \pm 2.883$ & $3.225 \pm 2.809$ & 0.001 \\
\hline $\begin{array}{l}\text { Concerns regarding acquiring COVID-19 } \\
\text { (Mean } \pm \text { Std.Dev) }\end{array}$ & $4.873 \pm 2.811$ & $4.275 \pm 3.076$ & 0.082 \\
\hline $\begin{array}{l}\text { Overall wellbeing during lockdown } \\
\text { (Mean } \pm \text { Std.Dev) }\end{array}$ & $6.675 \pm 2.389$ & $7.113 \pm 2.676$ & 0.136 \\
\hline
\end{tabular}

Comparison of health conditions and concerns among patient groups. We compared the countinous variables(NRS questions) using T-test and categorical variables using Chi-square test. All test were twotailed, with significance level of $p<0.05$.

Among the six questions, two questions were of dichotomous types, which enquired on the incidence of flare of symptoms during the lock down and about the perspective of patients on their additional risk of acquiring COVID-19 infections while visiting a healthcare setting.

Among the respondents, 76 patients reported that they had their symptoms flared during this lockdown. A totol of $27.38 \%$ of patients with cardiovascular metabolic co-morbidities and $23.23 \%$ of patients with autoimmune rheumatic diseases had their symptoms flared during the lockdown days $(P>0.05)$. The perspective of the patients on their additional risk of acquiring COVID-19 infections while visiting a healthcare setting was also assessed. Patients with cardiovascular metabolic co-morbidities (65.60\%) 
and those with autoimmune rheumatic diseases (59.85\%) claimed that they might have an additional risk of acquiring COVID-19 infections while visiting a healthcare settings $(P>0.05)$.

Numerical rating scale was employed to assess the patient perspectives and concerns regarding reduced access to health care services, the medicines they used during COVID-19 season, anxieties of acquiring COVID-19 and their overall wellbeing during lockdown. The overall wellbeing of the patients in both patients groups were reported to be more than 5 , tending to the not satisfactory or worried range. All other characteristics that were assessed, reported to be in the satisfactory or not worried range in either of the study groups. The patients in the cardiovascular metabolic co-morbidities reported to have concerns regarding the medicines they use in the range of $4.344 \pm 2.883$, in contrast such concerns were only in the range of $3.225 \pm 2.809$ among patients with autoimmune rheumatic diseases $(P<0.05)$

Table 3 : Comparisons of health conditions and concerns among patient groups 


\begin{tabular}{|c|c|c|c|c|}
\hline $\begin{array}{l}\text { Questions asked } \\
\text { regarding health care } \\
\text { service utilization }\end{array}$ & $\begin{array}{l}\text { Options for } \\
\text { respondents }\end{array}$ & $\begin{array}{l}\text { cardiovascular } \\
\text { metabolic co- } \\
\text { morbidities }(n=157)\end{array}$ & $\begin{array}{l}\text { Autoimmune } \\
\text { rheumatic } \\
\text { diseases(n=142) }\end{array}$ & $\begin{array}{l}P \\
\text { value } \\
(2- \\
\text { tailed } \\
\text { test) }\end{array}$ \\
\hline \multirow{2}{*}{$\begin{array}{l}\text { Consulted the } \\
\text { Physician during the } \\
\text { lockdown }\end{array}$} & Yes(n=184) & $82(52.22 \%)$ & 102(71.83\%) & \multirow[t]{2}{*}{0.000} \\
\hline & No(n=115) & 75(47.77\%) & $40(28.16 \%)$ & \\
\hline \multirow{2}{*}{$\begin{array}{l}\text { Did you have access to } \\
\text { telemedicine during } \\
\text { lockdown }\end{array}$} & Yes $(n=169)$ & 72(45.85\%) & $97(68.30 \%)$ & \multirow[t]{2}{*}{0.000} \\
\hline & No(n=130) & $85(54.41 \%)$ & $45(31.69 \%$ & \\
\hline \multirow{2}{*}{$\begin{array}{l}\text { Conducted regular lab } \\
\text { test during the } \\
\text { lockdown }\end{array}$} & Yes $(n=184)$ & $82(52.22 \%)$ & 102(71.83\%) & \multirow[t]{2}{*}{0.171} \\
\hline & No(n=115) & 75(47.77\%) & $40(28.16 \%)$ & \\
\hline \multirow{2}{*}{$\begin{array}{l}\text { Were the medicines } \\
\text { available in local } \\
\text { pharmacy }\end{array}$} & Yes(n=168) & 124(78.98\%) & $44(30.98 \%)$ & \multirow[t]{2}{*}{0.000} \\
\hline & No(n=131) & $33(21.01 \%)$ & 98(69.01\%) & \\
\hline \multirow[t]{5}{*}{$\begin{array}{l}\text { Strategies followed to } \\
\text { continue the } \\
\text { medications }\end{array}$} & $\begin{array}{l}\text { Depended on } \\
\text { Accredited Social } \\
\text { Health Activists } \\
\text { (ASHAs) }(n=25)\end{array}$ & 15(9.55\%) & $10(7.04 \%)$ & \multirow{5}{*}{0.072} \\
\hline & $\begin{array}{l}\text { Relatives bought the } \\
\text { medicine for the } \\
\text { patient }(n=105)\end{array}$ & $65(41.40 \%)$ & $40(28.16 \%)$ & \\
\hline & $\begin{array}{l}\text { Went and bought the } \\
\text { medicines on their } \\
\text { own( } n=116)\end{array}$ & $53(33.75 \%)$ & 63(44.36\%) & \\
\hline & $\begin{array}{l}\text { Already had enough } \\
\text { medicines }(n=41)\end{array}$ & 17(10.82\%) & $24(16.90 \%)$ & \\
\hline & $\begin{array}{l}\text { Discontinued the } \\
\text { medicines }(n=12)\end{array}$ & $7(4.45 \%)$ & $5(3.52 \%)$ & \\
\hline \multirow{4}{*}{$\begin{array}{l}\text { The most accessible } \\
\text { health care } \\
\text { professional during the } \\
\text { lockdown }\end{array}$} & Doctor(n=123) & $42(26.75 \%)$ & $81(57.04 \%)$ & \multirow{4}{*}{0.000} \\
\hline & Nurse(n=25) & 17(10.82\%) & $8(5.63 \%)$ & \\
\hline & Pharmacist(n=45) & 17(10.8\%) & 28(19.71\%) & \\
\hline & Others $(n=106)$ & $81(51.59 \%)$ & 25(17.60\%) & \\
\hline
\end{tabular}

Comparison of health care utilization among patient groups. We compared categorical variables using Chi square test. All test were two- tailed, with significance level of $p<0.05$.

Health conditions and concerns during COVID-19 lockdown days 
Independent Factors associated with missing health care (Physician Visit)

The independent factors associated with missing health care access were assessed. The risk factors associated with missing health care was the cardiovascular metabolic co-morbidities and the patients with no flare of symptoms ( $p$ value $<0.05$ ).

\section{Table 4 : Independent Factors associated with missing health care}

\begin{tabular}{|c|c|c|c|c|}
\hline \multirow[t]{2}{*}{ Parameter } & \multirow[t]{2}{*}{$\begin{array}{l}P \\
\text { value }\end{array}$} & \multirow[t]{2}{*}{$\begin{array}{l}\text { Odds } \\
\text { Ratio }\end{array}$} & \multicolumn{2}{|c|}{$\begin{array}{l}95 \% \text { Cl for } \\
\text { Odds Ratio }\end{array}$} \\
\hline & & & $\begin{array}{l}\text { Lower } \\
\text { Limit }\end{array}$ & $\begin{array}{l}\text { Upper } \\
\text { Limit }\end{array}$ \\
\hline Age & 0.329 & 1.010 & 0.990 & 1.030 \\
\hline Sex , Male (Ref=Female) & 0.368 & 0.760 & 0.418 & 1.381 \\
\hline $\begin{array}{l}\text { Chronic disease[cardiovascular metabolic co-morbidities (Ref= } \\
\text { Autoimmune rheumatic diseases)] }\end{array}$ & 0.004 & 2.882 & 1.400 & 5.930 \\
\hline Hospital sector [Government, (Ref=Private)] & 0.694 & 1.280 & 0.374 & 4.381 \\
\hline Physician [General,(Ref=Specialist)] & 0.978 & 0.985 & 0.320 & 3.025 \\
\hline Availability of medicines in local pharmacy[Yes (Ref=No)] & 0.959 & 0.958 & 0.425 & 2.466 \\
\hline Flare of symptoms during lockdown[Yes, (Ref=No)] & 0.000 & 0.198 & 0.086 & 0.459 \\
\hline $\begin{array}{l}\text { Worried about acquiring COVID-19, If they visit hospitals[Yes, } \\
\text { (Ref=No)] }\end{array}$ & 0.146 & 0.638 & 0.348 & 1.170 \\
\hline Concerns regarding the medicines they use in COVID-19 season & 0.647 & 0.967 & 0.836 & 1.118 \\
\hline Concerns regarding acquiring COVID-19 & 0.095 & 1.149 & 0.976 & 1.353 \\
\hline Overall wellbeing during COVID-19 lockdown & 0.713 & 1.022 & 0.911 & 1.146 \\
\hline
\end{tabular}

Independent predictors of missing regular health care (Physician Visit) : Binary logistic regression was used the assess the independent predictors of missing regular health care. We used dichotomous variable and numerical rating scales (NRS).Dichotomous variables are assessed with by considering their reference variable. The numerical rating scales ranged from 0 to 10 . In this 0 was rated as not worried or satisfactory and 10 as worried or not satisfactory.

\section{Discussion}

COVID-19 has terrified entire health care system of the world. This pandemic exposed the pitfalls of almost countries in their preparedness to face a health emergency. One of the less addressed issues 
during this COVID-19 is the reduction in health care access for chronic disease treatments as most of the hospitals were converted to COVID-19 care centres.

India had been in complete lockdown for about 2 months to eradicate the spread of the COVID-19 in the nation. This long period of lock down had paved difficulty for the chronic disease patients to continue their treatment. We assessed the health conditions of chronic disease patients and their assess ability to medical care during the hard days of lock down. Our study was conducted on the two categories of chronic diseases. Our survey had 299 eligible respondents for the study. 157 respondents were from the cardiovascular metabolic co-morbidities whereas 142 respondents were in autoimmune rheumatic diseases category. We had considered the patients who have both cardiovascular metabolic comorbidities and autoimmune rheumatic diseases to be in autoimmune rheumatic disease category since patients with both these diseases might have predominant symptoms of autoimmune rheumatic disease and most of their response will be in accordance with the autoimmune rheumatic disease. The incidence of the cardiovascular metabolic co-morbidities is also having an association with the inflammation pathway of autoimmune rheumatic diseases [6]. Because of all these reasons we included the patients with both these chronic diseases in the group of autoimmune rheumatic diseases.

The mean age of patients in cardiovascular metabolic co-morbidities group was found to be $59.19 \pm$ 16.34 and those in autoimmune rheumatic diseases was $47.05 \pm 13.30$. The mean age of patients with chronic diseases was below 60 years. The comparatively younger age of patients can be attributed because of our method of data collection. As we used social media for data collection there are high chances of missing out majority of the elderly population since the accessibility of such social Medias are less for the elder patients.

The predominant distribution of female gender for cardiovascular metabolic co-morbidities (57.32\%) group and autoimmune rheumatic diseases $(72.53 \%)$ is in accordance all the previous studies in this field.[7,8,]. The women are found to react more negatively in terms of to the same traumatic stress when compared with men[9]. This alerts the demanding needs of continuous access of health care to these groups as women are most vulnerable population that is effected by a natural disasters like COVID-19.

In the cardiovascular metabolic co-morbidities patients, the majority of them had an educational background of under graduation and high school level in contrary patients in the autoimmune rheumatic diseases had an educational background post graduation and under-graduation level. The higher educational status of autoimmune rheumatic disease patients were reflected in their adherence with the treatments in terms of regular physician checkups and laboratory test. Apart from better educational status the opportunity of telemedicine that was accessed by the autoimmune rheumatic diseases (68.30\%) patients were also helpful for the better adherence with the treatment in this group. Thus telemedicine is found to be promising and can be extended to other fields of chronic diseases for the better adherence and continuation of their treatment. The higher proportions of patients in the autoimmune rheumatic diseases group depended on the private sector hospitals and specialised Physicians for their treatment when compared to the other group of patients. 
The patients were enquired regarding the availability of their medicines in their local pharmacy. $78.98 \%$ of the patients in the cardiovascular metabolic co-morbidities group procured their medicines from the local pharmacy in contrary only $30.98 \%$ of patients in the autoimmune rheumatic diseases group could procure their medicines from their local pharmacies. The unavailability of the drugs for the autoimmune rheumatic disease patients can be attributed to the comparatively less prevalence of the disease in the community, higher cost of the biological drugs and comparatively higher cost of storage for such drugs[10]. These results points to the added responsibility of the government to ensure the supply of these life saving medicines especially at the door step of the patients during the conditions of such natural disasters.

Our study also analysed the medicine supply strategies that was provided for the chronic disease patients. Majority of the patients in both the disease group relied either on their own or depended on their relatives to buy their medicines. But both these options of procuring the medicines would lead these venerable groups of patients to an increased risk of getting these infections. One of the methods a small group of these patients depended was the service of Accredited Social Health Activists (ASHAs) for their medicine supply. This ASHA workers services shows some promising scopes for handling such health emergency scenario. ASHAs are the community health worker's cadre in India which is designed to facilitate the grass route level health care activities of the maternal and child health in the community [11]. The ASHA workers are already in place, scouring for the patients with communicable disease and keeping surveillance on the quarantined patients in their area in the COVID-19 pandemic [12]. Hence there has to be effective measures in place to provide the medicines via these ASHA workers for the chronic disease patients.

The majority of patients in both these chronic disease groups worried regarding the increased chances of acquiring COVID-19 infections. This reflects the general knowledge regarding the COVID-19 infections among the common population. This general awareness can be considered as the positive result of " Break the chain" campaign launched by Kerala state government, which aims in educating the general public regarding the essentiality of washing the hands, using face mask and need of social distancing[13].

The NRS based questions proved that the concerns regarding the medicines they use in COVID-19 season was higher in cardiovascular metabolic co-morbidities group than in the autoimmune rheumatic disease patients $(P$ value $<0.05)$. This is assumed to have a positive correlation with the private hospital sectors from were majority of the autoimmune rheumatic disease patients take their treatment. This can be due to the service of specialised clinical pharmacist that are employed in the private hospital sectors to educate the patients regarding the medicines and resolve the concerns regarding their medication use. Such post has to be created in the government sectors for the better outcomes

\section{Conclusion}


In conclusion there is strong need for health policy reformations in the field of the chronic diseases health care management to equip the preparedness in order respond adequately to such medical emergencies including natural disaster.

\section{Declarations}

Conflict of Interest: Authors declare there is no conflict

Funding: No funding

Ethical statement: We obtained informed consent from all the participants of the study. Ethical permission cannot be given due to COVID-19 lockdown because that consent has to be given by a group of persons

Availability of data and materials: The datasets used or analysed during the current study are available from the corresponding author on reasonable request,

Authors contribution:

Aby Paul \& Jobin Kunjumon designed the study

Sanjo saijan , Basil John , Stelvin Sebastian and Edwin Antony circulated and collected the data

Joel Joby and Jude James did the statistical analysis and compiled the manuscript

Consent for publication: We provide the complete consent for publication to the journal of Military Medical Research

Acknowledgements: We acknowledgement the entire staff of Nirmala college of Pharmacy, Muvattupuzha for their continuous motivation and mentorship for our survey

\section{References}

1. World Health Organization. Naming the coronavirus disease (COVID-19) and the virus that causes it 2020 [31/03/2020]. Available from: https://www.who.int/emergencies/diseases/novel-coronavirus2019/technical-guidance/namingthe-coronavirus-disease-(covid-2019)-and-the-virus-that-causes-it.

2. Li B, Yang J, Zhao F, Zhi L, Wang X, Liu L, et al. Prevalence and impact of cardiovascular metabolic diseases on COVID-19 in China. Clin Res Cardiol. 2020. Epub 2020/03/13. doi: 10.1007/s00392-02001626-9. PubMed PMID: 32161990.

3. Pope JE. What Does the COVID-19 Pandemic Mean for Rheumatology Patients? [published online ahead of print, 2020 Apr 30]. Curr Treatm Opt Rheumatol. 2020;1-4. doi:10.1007/s40674-020-00145y 
4. 4.Shivani Phaugat( June 3 , 2020). India Lockdown 5.0: Covid-19 unlock action plan.ETCFO. retrieved from https://cfo.economictimes.indiatimes.com/news/india-lockdown-5-0-covid-19-unlock-actionplan/76167820

5. R. Agca, L.H.G.A. Hopman, K.C.J. Laan, V.P. van Halm, M.J.L. Peters, Y.M. Smulders et,al . Cardiovascular Event Risk in Rheumatoid Arthritis is Higher than in Type 2 Diabetes: a 15 Year Longitudinal Study, The Journal of Rheumatology May 2019, jrheum.180726; DOl: 10.3899/jrheum. 180726

6. Wolff R, Fefer P, Knudtson ML, et al. Gender differences in the prevalence and treatment of coronary chronic total occlusions. Catheter Cardiovasc Interv. 2016;87(6):1063-1070. doi:10.1002/ccd.26330

7. 7.. Blitshteyn S. Autoimmune markers and autoimmune disorders in patients with postural tachycardia syndrome (POTS). Lupus. 2015;24(13):1364-1369. doi:10.1177/0961203315587566

8. V Yilmaz, S Cangur, HE ClikSex difference and earthquake experience effects on earthquake victims Personality and Individual Difference, 39 (2) (2005), pp. 341-348

9. 9.Pasma A, Schenk C, Timman R, et al. Does non-adherence to DMARDs influence hospital-related healthcare costs for early arthritis in the first year of treatment?. PLoS One. 2017;12(2):e0171070. Published 2017 Feb 2. doi:10.1371/journal.pone.0171070

10. Saprii L, Richards E, Kokho P, Theobald S. Community health workers in rural India: analysing the opportunities and challenges Accredited Social Health Activists (ASHAs) face in realising their multiple roles. Hum Resour Health. 2015;13:95. Published 2015 Dec 9. doi:10.1186/s12960-0150094-3

11. 11.Vishnu Varma(May 5,2020 ) The foot soldiers of Kerala's Covid- 19 battle, 26,000 women who won't overlook any detail. Retrieved from https://indianexpress.com/article/facebook-stories-ofstrength-2020/governing-the-crisis/the-foot-soldiers-of-keralas-covid-19-battle-25000-women-whowont-overlook-any-detail-6394687/

12. Jeemon Jacob(March 15,2020) Break The Chain: Kerala launches mass handwashing campaign against Covid-19 pandemic. Retrieved from https://www.indiatoday.in/india/story/break-the-chainkerala-launches-mass-handwashing-campaign-against-covid-19-pandemic-1655819-2020-03-15 